\title{
Teaching of the Theme "Manas and Manastelling Skill" by Critical Thinking Method Strategies
}

\author{
Gulzat Tolonova1, Gulnaz Borubekova², Busharipa Ukueva33, Umirkhon Alibekova4, \\ Rakhat Bekmuratova', Begaiym Baiieva5 ${ }^{5}$, Zhamila Imaralieva', Samara Ismailova ${ }^{6}$, \\ Kanyshai Chotikeeva ${ }^{7}$, Zhypargul Abdullaeva ${ }^{8^{*}}$ (1)
}

\footnotetext{
${ }^{1}$ Department of Language Education, College of Finance and Jurisprudence, Osh State University, Osh, Kyrgyzstan

${ }^{2}$ Department of Kyrgyz and Russian Languages, Osh Technological University, Osh, Kyrgyzstan

${ }^{3}$ Department of Pedagogics, Osh State University, Osh, Kyrgyzstan

${ }^{4}$ Department of Kyrgyz Language and Literature, Kyrgyz Uzbek University, Osh, Kyrgyzstan

${ }^{5}$ Professional College, Kyrgyz Uzbek University, Osh, Kyrgyzstan

${ }^{6}$ Department of Essential Pedagogics, Kyrgyz Uzbek University, Osh, Kyrgyzstan

${ }^{7}$ Department of Kyrgyz Language and Literature, Medical College, Osh State University, Osh, Kyrgyzstan

${ }^{8}$ Science and Research Department, Osh State University, Osh, Kyrgyzstan

Email: ^jypar.science@oshsu.kg
}

How to cite this paper: Tolonova, G., Borubekova, G., Ukueva, B., Alibekova, U., Bekmuratova, R., Baiieva, B., Imaralieva, Z., Ismailova, S., Chotikeeva, K., \& Abdullaeva, Z. (2020). Teaching of the Theme "Manas and Manastelling Skill" by Critical Thinking Method Strategies. Open Journal of Modern Linguistics, 10, 675-684. https://doi.org/10.4236/ojml.2020.106042

Received: October 27, 2020

Accepted: November 17, 2020

Published: November 20, 2020

Copyright $\odot 2020$ by author(s) and Scientific Research Publishing Inc. This work is licensed under the Creative Commons Attribution International License (CC BY 4.0).

http://creativecommons.org/licenses/by/4.0/

\begin{abstract}
This article is investigating the critical thinking method in the teaching of the theme "Manas and manastelling skill" by zigzag strategy. For the setting of the critical thinking tasks during teaching, various questions about four different texts were analyzed by students using the Venn diagram, cinquain, cluster, and crossword strategies. This method is recommended for teaching and the object recognition of the theme "Manas and manastelling skill" in the education process. In this work, students have tested practically an approach for an independent understanding of the theme and its interpretation to each other. Students were able to develop their organizational skills, ability to work individually, in pairs, and in groups.
\end{abstract}

\section{Keywords}

Teaching, Epic Manas, Critical Thinking, Manastelling Skill, Improvisation, Ability

\section{Introduction}

Heroic Epic of Manas is characterizing the flavor of the original Kyrgyz culture in particular of a nation containing language, traditional and moral principles 
(Zhumaliev, 2013). Activities of the Kyrgyz epic hero Manas in the Talas region were narrated more than 1000 years ago (Light, 2018). Epic of Manas is the globe incomparably great saga. It is a spiritual treasure describing historical and heroic events, artistically illustrating hundreds of images and characters, incomparable to other epics (Figure 1).

During the teaching of the Manasology subject to university students, some functional approaches are not matching with initially set goals, aims, and contents of the competent specialist development. To achieve the necessary results it is important to design educational strategies based on students learning styles to improve their critical thinking and problem solving skills (Shirazi \& Heidari, 2019).

We choose the critical thinking method in teaching for advantages in the development of student's individual, pair and group working skills, as well as freely express their opinions.

\section{Theory of Critical Thinking}

The critical thinking method is applied in the development of students' higher-order cognitive skills such as conceptualization, analysis, and evaluation; connected with philosophical concepts of individual, personality traits, mind habit characteristics (Pu et al., 2019). Collaborative learning by reading and writing is an effort of educators around the world that fosters students' positive interdependence, individual accountability, and interpersonal skills to develop critical thinking (Gokhale, 2012). The main purpose of this collaboration is to introduce teaching methods promoting the development of critical thinking skills of students regardless of their age into pedagogy. There is a set of learning conditions that contribute to the formation of critical thinking skills (Figure 2).

Critical thinking is a complex process, for this reason, most teachers believe that only the upper grade students are capable of this. However, in practice, adolescents are also able to participate in the analysis of complex problems and the making of high-level decisions. Thinking itself is a process similar to reading,

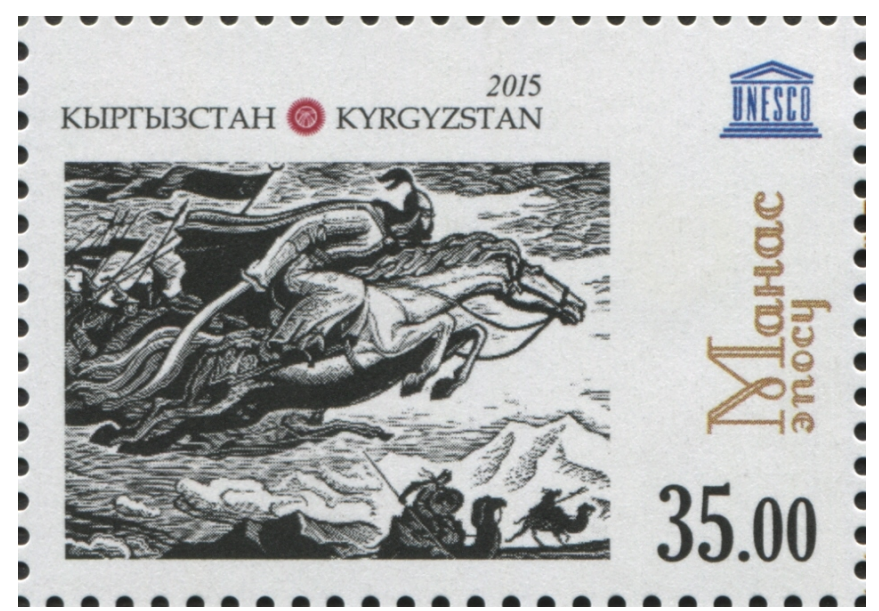

Figure 1. Manas on the "Chon Kazat" hunting. 


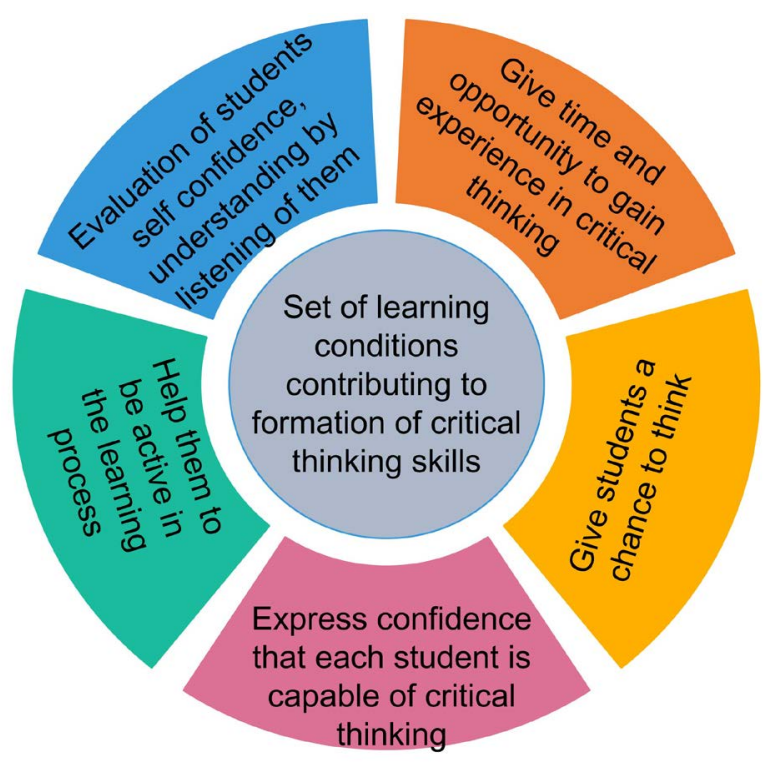

Figure 2. Set of learning conditions contributing to the formation of students' critical thinking skills.

writing, speaking, and listening; but an active coordinated complex process that involves thinking about real things. Some behavioral models and attributes can be supported and nurtured in the audience: 1) Self-confidence; 2) Active participation; 3) Communication with teachers and peers; 4) Listening to others including additional criteria of advantages and consequences of critical thinking shown in Figure 3.

Conducted research showed how a college curriculum and teaching strategies could be developed to enhance critical thinking (McMillan, 1987). It was suggested that critical thinking ability is a central element in college students' lifelong learning (Terenzini et al., 1995). According to the terminology, the word "critical" means "to find fault with what others do or say", while the word "thinking" means an individualistic approach (Hansson, 2019).

In this article, we are describing progress in the college students' creativity and obtained knowledge by use of the critical thinking method zigzag strategy including Venn diagram, cinquain, cluster, and crossword.

\section{Research Methods}

The teaching of the Manasology subject to college students and the development of scientific-methodologic fundamentals in professional specialists preparation implemented through critical thinking method strategies such as observation, thinking, comparing, proving, modeling, schematization, etc. The critical thinking method is widely used in college students' teaching. We have used the following competencies as an object of Manas epic narrators' recognition during the Manasology subject:

- Shaping out of students' speech, oral and written language, and ability to build a logical and understandable reason. 


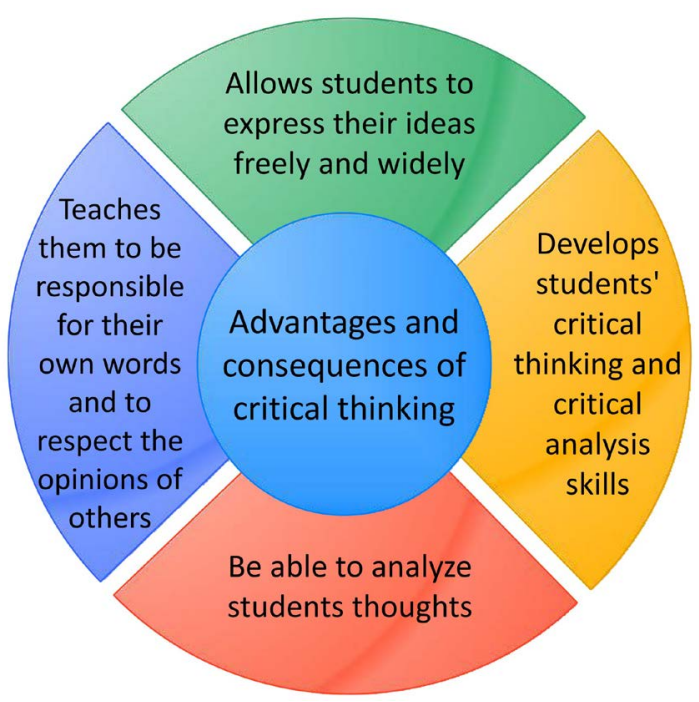

Figure 3. Additional criteria for critical thinking advantages and consequences.

- To respect people according to the accepted moral and legal norms based on social interaction, knowledge, and non-verbal skills.

- An ability to promote the culture of tolerance and partnership.

\section{Expected Teaching Results}

- Deeply understand thematic content of the epic Manas.

- Students should know about the influence of historical epochs on the Manas epic formation.

- Introduction of students into initial information about epic Manas.

- Students should know closely about the legendary manastellers.

- Students should know about the main stories in the whole trilogy of the epic Manas.

- Define and identify versions of epic Manas by manastellers.

- Analyze character systems in the epic Manas.

\section{Results and Discussions}

The main part of Manasology class taught by using the critical thinking method through zigzag strategy. During the use of this method, students can understand and accept the information independently and explain the learned information to their classmates (Muratov \& Akmatov, 2017). Students can develop their abilities and skills in working with text. At the beginning of class, students were divided into four groups. The teacher distributed the following text portions to students:

Text 1: Manasteller is a poet and improvisator, author and actor, singer, and playwriter, a person with a strong creative personality. Not every person has such a miracle strength. This property was granted by Allah to his lovely person as a gift. Therefore, Mukhtar Auezov named a legendary manasteller Sayakbai Karalaev as a "Gomer of $20^{\text {th }}$ century". Chyngyz Aitmatov said about the saga 
"Manas" told by Sayakbai Karalaev "the largest ocean of poetry and the human spirit", and had compared with the endless ocean. Nevertheless, none can deny that the saga "Manas" is poetic hill binding together people who created this saga with earth and the universe. This was proved by the Guinness World Records book in which it was written: "The longest poem is the Kyrgyz national epic Manas published as a book in 1958. It has a volume of 500 thousand lines". That is why Kyrgyz people can be proud of the epic Manas in front of people of the world. At that time, this outlined definition was given only to the trilogy book of "Manas", "Semetey" and "Seytek" told by the Sayakbai Karalaevs version. But, formerly more than 60 manuscript versions of other manastellers were kept in the National Academy of Sciences. According to the accurate data, more than 80 versions from which each one has separate features are storing in the foundation now (Ukueva, 2017).

Text 2: Manastelling skill is a mysterious phenomenon in the culture of Kyrgyz people. It is known from the ancient epochs, that this skill was granted to manasteller as a vision. Overviewing of this sacral vision lets us say that, it is historical or genetic memory and secret knowledge. From ancient times, our ancestors based on their mental knowledge had considered that manastelling skill is purifying the human spiritual soul and bound with higher consciousness. That is why from a long time ago manastellers had been evaluated as people possessing special ability. For example of Sagymbai Orozbak uulu, Aziz Omur uulu, Mambet Chokmor uulu, Sayakbai Karala uulu, Nazar Bolot uulu, Chouke Omur uulu, Balugooz Kumar uulu were known as "zhaichylyk" (from the ancient Turkish yadachi-“magician", "conjuring”) (Akmataliev, 2015), predicting the future and extrasensory feeling people, best diplomats, and advisors of politician leaders. Especially in the $19^{\text {th }}$ century, one of spectacular manastellers Tynybek Zhapyi uulu was simultaneously a politician and the Tynymseyit genus leader. Such custom and unseen manastelling skills differ by reflecting the mental (intellectual), materialistic, and spiritual levels (Ukueva, 2017).

Text 3: Each manasteller is a unique and talented individual divided into the following types depending on their different dasmiyas and the miraculous properties:

1) Amateur manastellers are who memorize others' portion of Manas epic and told himself.

2) Incomplete manastellers are who learned the portion of epic Manas or part of it from other tellers.

3) True manastellers are who well studied the main stories of an epic and tell them from the beginning to the end by his understanding, for example, Moldobasan Musulmankulov, Shapak Rysmendeev, and Togolok Moldo.

4) Great manastellers are who possess great talent and skills, creator of the top idea and systematic story in the epic version, well known to other people, and earned a great reputation. S. Orozbakov, S. Karalaev can be considered as great manastellers. Especially, the largest version by volume belongs to S. Orozbakov. His only "Manas" is a 180,378 line poem. The difference of his version from other versions is the domination of broad descriptions about Kyrgyz people an- 
cient custom rules, i.e. wedding, public meal, to marry a daughter, matchmaking, etc. Distinct and beauty is the prevalence of Islamic religious beliefs.

5) Handwriting manastellers are Togolok Moldo, Ybrai Abdurakhmanov, and Chinese manasteller from Kyzyl-Suu Zhusup Mamai. These manastellers wrote their versions on paper completely (Ukueva, 2017).

Text 4: "Narrators school in folkloristics can be defined as a group of manastellers whose versions are significantly distinct, have a close meaning and similar to other manastellers versions, which were resulted from the creative influence of known epic poem tellers to each other, students' education and learning from a teacher". Kyrgyz folkloristics is composed of the North and West schools. According to the settled area division as Naryn and Karakol by M. Auezov, a comparison of "Manas" epic versions revealed similarity between Sagymbai Orozbak and Shapak, Bagysh, T. Moldo, Moldobasan versions; between Sayakbai Karala uulu and Mambet, Duncan, Shaabai, Kaaba versions. There are similarities in epic versions between Tynybek (school) from Naryn and Sagymbai, T. Moldo versions due to their strong influence. Moldobasan, Ybyraim, and Bagysh are belonging to the Sagynbais narration school (Musaev, 1979). However, it is not mandatory to include Sagynbai and his teacher Tynybek into Naryn School. There is no doubt about possible similarities in this school of manasteller stories due to their travels and narrations in many areas and learning from great manastellers. For example, a comparison of Mambet Chokmor uulu and Syayakbais versions revealed similarities in their stories. Two manastellers, Mambet and Sayakbai are considering as their teachers the Donuzbai and Choyuke. Zhanybai Kojekov is considered as a master of "Semetey" and "Seytek" in the West, while M. Kalbaev, Shaymardan, Ch. Sydykov, K. Zhumahgulov, and B. Sultanov were included in the Choodan manastellers book (Ukueva, 2017).

Students were introduced to the working approach of this method by a teacher, and work through the following steps:

Step 1. Students were be numbered as 1, 2, 3, and 4 by the teacher and gathered as four groups according to their numbers.

Step 2. Each group received from the teacher four different texts (as shown above). Students of group one read Text 1, students of group two read Text 2, students of group three read Text 3 and the students of group four read Text 4 .

Step 3. In the established period, each student read his portion of the text individually.

Step 4. Each group had chosen one student as a leader who presented the text to other students in the group. Everyone had listened to the group leaders' presentation with attention, and note unclear words for discussion at the end.

Step 5. Again, students were renumbered as 1, 2, 3, 4 in those groups, and gathered as new four groups according to their numbers.

Step 6. Each student came from the initially numbered groups explained his text to other students in the new group.

Step 7. Here each student in the new group was informed about the contents of all four texts given by the teacher at the beginning of class. 
Step 8. After that, students came back to their initial groups and present texts in the following order: $1^{\text {st }}$ group made a presentation of Text 1 by using of cinquain strategy developing students' critical writing skills and reflection (Abdrakhmanova et al., 2017). An example of cinquain used in this class is:

- Sayakbai

- Proper, strong

- Unique, imagine, tell

- Great epic teller person

- Manasteller

Students of the 2nd group made a presentation of Text 2 by using the Venn diagram which used to motivate and encourage discussion about similarities and differences between manastellers (Hoffman, 2001; Davies \& Barnett, 2015), as shown in Figure 4.

Students of the 3rd group made a presentation of Text 3 by using the cluster analysis strategy to identify distinct subgroups (Duff \& Marriott, 2017) of manastellers (Figure 5).

$4^{\text {th }}$ group students made a presentation of Text 4 by using the crossword strategy as it was shown in Figure 6.

Questions vertically:

1) Name of the great epic?

Questions horizontally:

1) Name of manasteller.

2) The name of Almanbets' wife in the epic Manas.

3) Name of the place where dead famous manasteller Tynybek Zhapyi uulu.

4) What was the name of Kanykeis' father?

5) Name of one from the Kyrk choro.

After text presentations, students asked and answered each other's questions. Functions and effects of critical thinking method used in the teaching of the theme "Manas and manastellers" are the following:

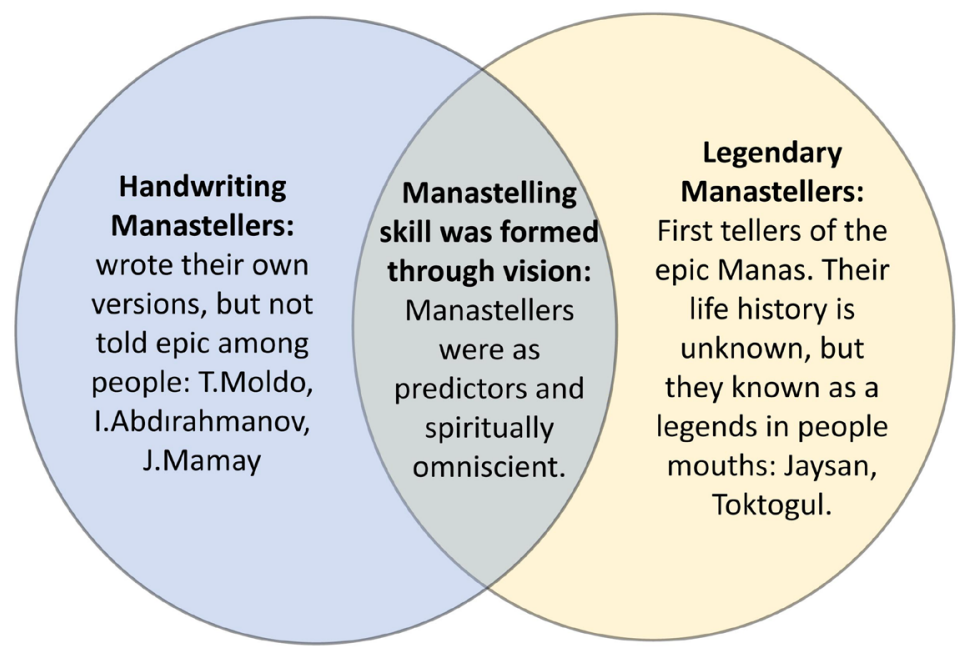

Figure 4. Venn diagram showing similarities and differences between manastellers. 


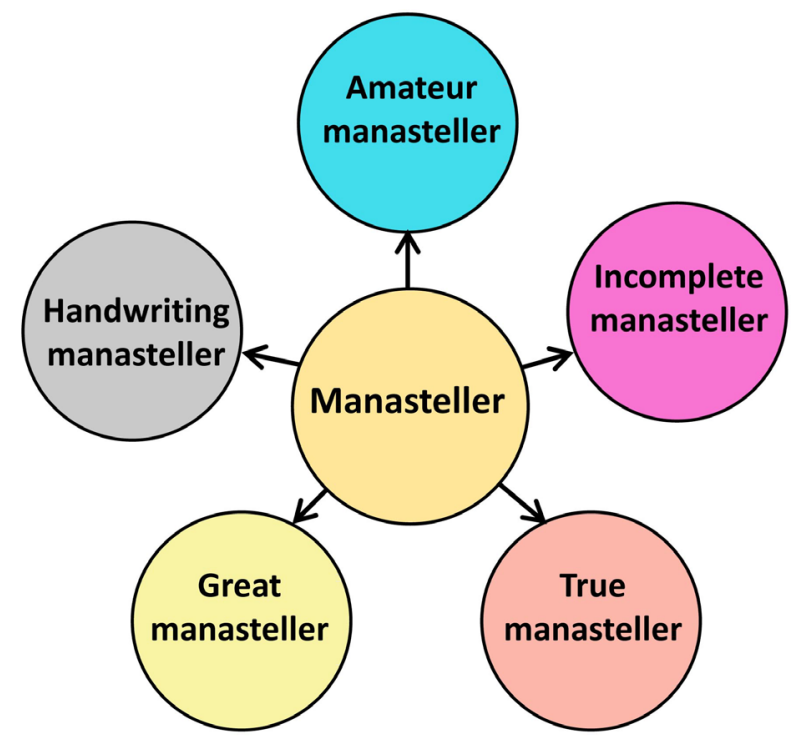

Figure 5. Cluster "Manasteller".

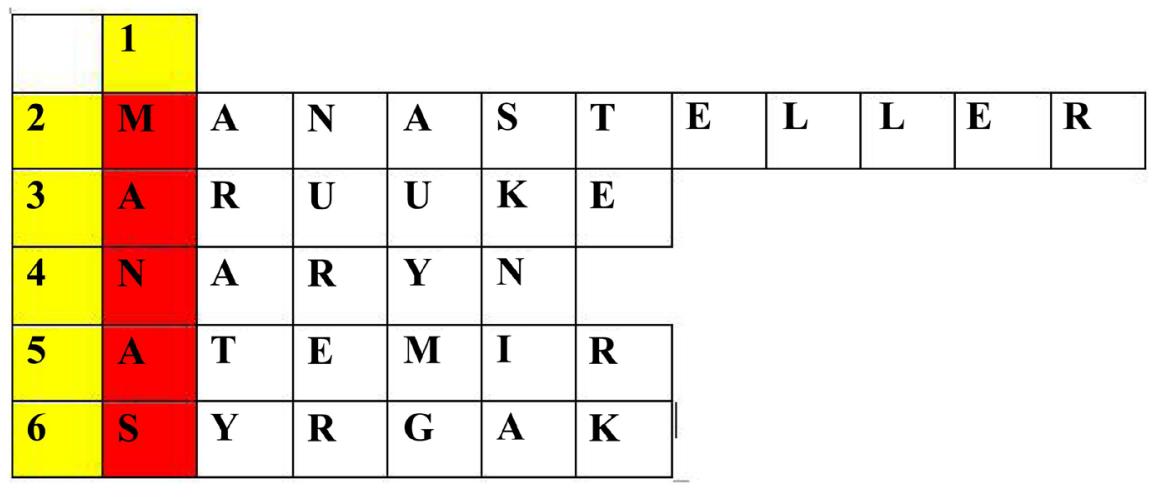

Figure 6. Crossword "Manas".

- In special secondary schools, using such critical thinking methods in life practice will help to improve students' creativity and analysis of scientific, theoretical aspects.

- In the application of the zigzag method, all students worked with creativity and talent. They heard each other's presentations and added their own opinions.

- To improve and deepen the students thinking class-related questions were asked. The teacher managed the time for each step. Each student in all four groups has participated in a discussion, where they had carefully listen to each other and think about the topic content. The teacher observed all four groups for giving the right direction to students.

- The superior point of using the critical thinking method in this class is an individual and group works of students by reading, understanding, thinking, discussing, expressing own opinion, explaining and creative working; at the same time acquired knowledge about the strategies of Venn diagram, cinquain, cluster, and the crossword. 


\section{Conclusion}

At the end of the class, students obtained the following knowledge about epos Manas: know about manastellers, their distinctive points from other people, and their role in folklore, types, differences, and divisions of manasstellers. Understand the uniqueness of the manastelling skill. The creation of students' creative activity skills should be practiced following the goal of each interactive lesson. The use of critical thinking strategies in the teaching of college students will promote the improvement of their activities, skills development, and deepens the quality of education. At the same time, students' perceptions using critical thinking method strategies will develop and progress. Each interactive class used for the motivation of students' creative activities following the set goals will be practiced.

The practical importance in this work was implemented by student's critical thinking abilities, analyzing their opinions and skills in making presentations by Venn diagram, cluster and crossword.

\section{Conflicts of Interest}

Authors have no conflict of interest in the publication of this paper.

\section{References}

Abdrakhmanova, S. T., Bazarbayeva, L. T., \& Sidikova, G. B. (2017). Development of Critical Thinking. European Journal of Natural History, 5, 52-55.

Akmataliev, A. (2015). Manas Encyclopedia (1400 p.). Bishkek: NAASKR.

Davies, M., \& Barnett, R. (2015). The Palgrave Handbook of Critical Thinking in Higher Education. New York: Palgrave Macmillan. https://doi.org/10.1057/9781137378057

Duff, A., \& Marriott, N. (2017). The Teaching-Research Gestalt in Accounting: A Cluster Analytic Approach. The British Accounting Review, 49, 413-428. https://doi.org/10.1016/j.bar.2017.05.001

Gokhale, A. A. (2012). Collaborative Learning and Critical Thinking. In N. M. Seel (Ed.), Encyclopedia of the Sciences of Learning (3641 p.). Boston, MA: Springer. https://doi.org/10.1007/978-1-4419-1428-6_910

Hansson, S. O. (2019). Critical Thinking. Theoria, 85, 3-7. https://doi.org/10.1111/theo.12179

Hoffman, E. A. (2001). Successful Application of Active Learning Techniques to Introductory Microbiology. Microbiology Education, 2, 5-11. https://doi.org/10.1128/154288101X14285805983179

Light, N. (2018). Kyrgyz Genealogies and Lineages: Histories, Everyday Life and Patriarchal Institutions in Northwestern Kyrgyzstan. Genealogy, 2, 53.

https://doi.org/10.3390/genealogy2040053

McMillan, J. H. (1987). Enhancing College Students' Critical Thinking: A Review of Studies. Research in Higher Education, 26, 3-29. https://doi.org/10.1007/BF00991931

Muratov, A., \& Akmatov, K. (2017). Learning New Technologies, Bishkek (320 p.).

Musaev, S. (1979). Epic Manas (201 p.). Frunze: Ilim.

Pu, D., Ni, J., Song, D., Zhang, W., Wang, Y., Wu, L., Wang, X., \& Wang, Y. (2019). In- 
fluence of Critical Thinking Disposition on the Learning Efficiency of Problem-Based Learning in Undergraduate Medical Students. BMC Medical Education, 19, Article No. 1. https://doi.org/10.1186/s12909-018-1418-5

Shirazi, F., \& Heidari, S. (2019). The Relationship between Critical Thinking Skills and Learning Styles and Academic Achievement of Nursing Students. The Journal of Nursing Research: JNR, 27, e38. https://doi.org/10.1097/jnr.0000000000000307

Terenzini, P. T., Springer, L., Pascarella, E. T., \& Nora, A. (1995). Influences Affecting the Development of Students' Critical Thinking Skills. Research in Higher Education, 36, 23-39. https://doi.org/10.1007/BF02207765

Ukueva, B. K. (2017). Manas Studies (143 p.). Bishkek.

Zhumaliev, K. (2013). Manas taanuu (152 p.). Bishkek. 